\title{
Lexical, morphological and syntactic development in toddlers between 16 and 30 months old: A comparison across European Portuguese and Galician
}

\section{Fernanda Leopoldina Viana}

University of Minho, Portugal

\section{Miguel Pérez-Pereira}

University of Santiago de Compostela, Spain

\section{Irene Cadime, Carla Silva, Sandra Santos and Iolanda Ribeiro \\ University of Minho, Portugal}

\begin{abstract}
The main aims of this study were to investigate the relationship between the lexical size and the emergence of morphological and syntactic markers in toddlers between the ages of 16 and 30 months and to compare these results between Galician and European Portuguese. Parents of 3012 Portuguese toddlers and those of 1081 Galician toddlers completed the MacArthur-Bates Communicative Development Inventory: Words and Sentences. The results indicated that the number of words, the ability to combine words and the number of different morphemes produced increased with age. The ability to combine words was used as an indicator of syntactic development; this ability was also associated with the toddlers' lexical size. In both samples, gender morphemes seemed to be the first to have their production generalized, followed by the plural and the past participle. The production of gender morphemes was accompanied by a small lexical size, whereas the imperfect tense and the person mark onset were associated with
\end{abstract}

\footnotetext{
Corresponding author:

Irene Cadime, Centro de Investigação em Estudos da Criança, Instituto de Educação, Universidade do Minho, Campus de Gualtar, 47I0-057 Braga, Portugal.

Email: irenecadime@ie.uminho.pt
} 
large lexical sizes. The implications of these results for charting the continuity between lexical, morphological and syntactical development are discussed.

\section{Keywords}

European Portuguese, Galician, lexical development, morphological development, syntactic development

\section{Introduction}

Children need to understand several words before they can start to produce them and say their first words around their first birthday (Bates et al., 1994). Although high interindividual variability exists in lexical development, a high percentage of children shows a vocabulary burst, i.e. a marked acceleration in the rate of word acquisition, usually when they are able to produce approximately 50 words; typically, this occurs around the age of 1;6 (Bleses et al., 2008; Stolt, Haataja, Lapinleimu, \& Lehtonen, 2008). The emergence of morphological and syntactic markers seems to occur later. For example, results from a study conducted by Simonsen, Kristoffersen, Bleses, Wehberg, and Jorgensen (2014) with Norwegian speakers indicated that grammatical skills were observable on average at age 1;7 and that the combination of words was the first grammar marker to emerge, given that approximately $50 \%$ of the sample combined words at this age stage. Past and present tenses and the plural were produced by $50 \%$ of their sample only about five months later (approximately age 2;1). Another study by Szagun, Steinbrink, Franik, and Stumper (2006), conducted with German-speaking toddlers, indicated that nouns, plural and gender marking are the first to be acquired (first signs of acquisition between ages $1 ; 6$ and $1 ; 9$ ), followed by case marking and main verb inflectional marking (past tense and past participle), which only seem to emerge around the second year of age.

Despite the enormous variability in the developmental patterns of language acquisition, not only in a quantitative way but also in a qualitative way (Nelson, 1973), a significant body of research provides evidence about the continuity and close relationships between first words and grammar development (Andonova, 2015; Bates \& Goodman, 1997; Caselli, Casadio, \& Bates, 1999; Devescovi et al., 2005; Marchman \& Bates, 1994; Mariscal \& Gallego, 2012; Simonsen et al., 2014; Szagun et al., 2006; Thordardottir, Weismer, \& Evans, 2002). Therefore, to understand language development we need to study not only the components of language but also their relationship, as they do not appear to be independent (Conboy \& Thal, 2006; Fenson et al., 2007; Labrell et al., 2014; Serrat, Sanz-Torrent, \& Bel, 2004).

A considerable body of empirical studies supports the hypothesis that lexical development not only precedes but also predicts future grammar development (e.g. Bates \& Goodman, 1999; Dromi, 1987; Marchman \& Bates, 1994). The seminal study by Marchman and Bates (1994), with a sample of 1130 monolingual English toddlers (aged between 1;4 and 2;6) conducted by using the MacArthur-Bates Communicative Development Inventories, showed that lexical size was a strong predictor of the frequency of regular and irregular verb production, as well as of the overgeneralized verb form production. The relationship between lexical development and some aspects of 
syntactic development, such as the ability to combine words, has also been observed. For example, Fenson et al. (1994), in a study conducted with English speakers, showed that $50 \%$ of the children with a lexicon size of 50-100 words had the ability to combine words, whereas this percentage rose to $95 \%$ when the toddlers' lexicon reached approximately 300 words. These results are interpreted as being consistent with the "critical mass hypothesis' (Marchman \& Bates, 1994; Plunkett \& Marchman, 1993), which states that a minimum repertoire of vocabulary is needed for the onset of grammar indicators. Bates and Goodman (1999) propose that grammatical abilities, such as the use of inflectional morphemes, emerge over the construction of a lexical system. A study conducted by Thordardottir et al. (2002) on Icelandic- and English-speaking two-year-old toddlers corroborates this idea, showing a continuity between lexical and grammatical development, and suggesting that a large critical mass of vocabulary is required before the appearance of grammatical regularity. In this sample, only children with a large vocabulary used a variety of suffixes and inflectional morphology.

Research that aims to study the interdependency of lexical and morphological development has been mainly conducted with native English-speaking children (Bates, Bretherthon, \& Snyder, 1988; Bates \& Goodman, 1997; Dale \& Goodman, 2005; Fenson et al., 1994), but similar effects have been observed in other languages. For example, Szagun et al. (2006) showed that the use of morphological markers starts to appear at a lexical size composed of 201-300 words and they continue to increase at higher levels of lexical capacity. Another study conducted in Spain (Mariscal \& Gallego, 2012), using a sample of 593 parents who were native speakers of Spanish as informants of the toddlers' linguistic abilities, indicated that the quantity of the vocabulary accounted for a significant amount of unique variance in noun morphology. Pérez-Pereira and García-Soto (2003) also found very high correlations between lexical size and the use of regular and irregular morphology in Galician-speaking toddlers.

Most of these studies have been conducted using the MacArthur-Bates Communicative Development Inventories (CDIs). These inventories, first developed in the United States (Fenson et al., 1994), use parents as informants of the toddlers' linguistic abilities, present good psychometric properties and are a robust and relatively cost-effective tool to assess large samples of individuals, which justifies their adaptation to more than 60 languages (for a list of the adaptations see http://mb-cdi.stanford.edu/adaptations.html). The CDIs are adapted for both European Portuguese and Galician, which allows for crosscultural and cross-linguistic comparisons of the language acquisition processes.

Galician is a language spoken in Galicia, a community located in the northwest of Spain, north of Portugal, and is genetically related to Portuguese. Both Galician and European Portuguese have the same origin and are Romance languages. Moreover, the two are pro-drop languages, use a relatively free word order (SVO), have gender markings and gender agreements, use subject-verb agreement, have a simple and regular plural system, and rich verb morphology, with person, number, tense-aspects and mood markings. Another common aspect is the existence of augmentative and diminutive markings on nouns and adjectives, and the use of pronouns after the verb in simple declarative or interrogative sentences although, in other sentences, such as negative or subordinated ones, the pronoun precedes the verb (Pérez-Pereira, 2008; Villalva, 2009). Due to the similarities of these languages, it is expected that the findings observed for the 
acquisition of Galician are similar to those observed for the acquisition of European Portuguese.

Therefore, given the close proximity between Galician and European Portuguese, the main aim of this study is to examine their similarities in respect of lexical, syntactic and morphological development, based on data collected on a large scale using the CDI. Moreover, this study aims to investigate the continuity between lexical and morphosyntactic development and to compare it in the two languages. Although this relationship has been investigated for several languages, additional evidence for other languages can provide further support for the universality of the interdependence between vocabulary and grammar modules.

The specific aims of the this study are the following: (1) to compare the lexical size of children from 16 to 30 months of age assessed with the Portuguese and Galician versions of the CDI; (2) to compare the results obtained in one score of syntactic development (combination of words) in children from 16 to 30 months of age in the Portuguese and Galician versions of the CDI; (3) to compare the production of seven regular morphemes in children from 16 to 30 months of age in the Portuguese and Galician versions of the CDI; (4) to relate the scores obtained in combination of words to the number of words produced and to compare them between languages; and (5) to analyse the age and lexical repertoire associated with the production of the different regular morphemes by $50 \%$ of the children (early acquisition) in each age group and to analyse the developmental trends in both languages.

\section{Method}

\section{Participants}

The Galician sample was composed of 1081 children aged between 16 and 30 months old (50.8\% were girls) and the Portuguese sample was composed of 3012 participants with ages between 16 and 30 months (47.3\% were girls). The Portuguese sample was the same as in Silva et al. (2017). A stratified sampling method was used for data collection in the Portuguese sample. Strata were defined according to the distribution of the population in the different geographic areas of Portugal, using the statistical data from the Censos 2011. Therefore, $36 \%$ of the participants were from the North of Portugal, $19.4 \%$ from the Centre, $27.4 \%$ from Lisbon, 5.3\% from Alentejo, 6.5\% from Algarve, 2.5\% from Madeira Island and 3\% from the Azores Islands.

Information regarding the maternal education of both samples is presented in Table 1. The Portuguese sample had higher maternal education levels compared to the Galician sample, $\chi^{2}(3)=444.61, p<.001$, with almost $40 \%$ of the sample having a university degree (see Table 1). In both samples, premature babies with low weight (less than 32 weeks of pregnancy and less than $1500 \mathrm{~g}$ ) or with severe medical conditions that could impair language development (e.g. Down syndrome) were excluded.

\section{Measure and procedures}

The Portuguese (Viana et al., in press) and the Galician (Pérez-Pereira \& García-Soto, 2003; Pérez-Pereira \& Resches, 2011) versions of the MacArthur-Bates Communicative 
Table I. Maternal education levels in each sample and population.

\begin{tabular}{lcccc}
\hline Maternal education & $\begin{array}{l}\text { \% Galician } \\
\text { sample }\end{array}$ & $\begin{array}{l}\text { \% Galician } \\
\text { population }^{\mathrm{a}}\end{array}$ & $\begin{array}{l}\text { \% Portuguese } \\
\text { sample }\end{array}$ & $\begin{array}{l}\text { \% Portuguese } \\
\text { population }^{\mathrm{b}}\end{array}$ \\
\hline No education & 1.1 & 2.8 & 0 & 2.3 \\
Primary & 35.7 & 13.3 & 9.5 & 39.7 \\
Secondary & 37.1 & 65.1 & 49.3 & 28.4 \\
University & 23.1 & 18.8 & 39.2 & 29.6 \\
No information & 3.0 & - & 2.0 & - \\
\hline
\end{tabular}

aPercentage for the Galician sample obtained from the IGE 2005.

bPercentage for the Portuguese population obtained from the Census 20II, considering the maternal education of Portuguese women aged between 20 and 45 years old.

Development Inventory: Words and Sentences (CDI-II) (Fenson et al., 2007) were used for data collection. The CDI-II is a self-report measure that is filled by the children's parents. It assesses the different aspects of the lexical, morphological and grammatical developments of children. For the purposes of this study, only three subsections of the instrument were used: (1) word production; (2) word endings (i.e. production of regular suffixes); and (3) syntactic development (i.e. word combination). The word production subscale is composed of 700 words in the Galician version and of 639 words in the Portuguese version. When responding to this subscale, parents had to mark which words from the checklist their child says spontaneously.

The word endings subscale assesses the ability of the children to produce regular morphemes and is composed of 10 items in the Portuguese version and nine items in the Galician one. In this study, only the seven common items of both versions of the CDI-II were considered. These seven items evaluate the spontaneous production of the following regular suffixes: plural, imperfect tense, past tense, past participle, gender, augmentatives and diminutives and person marking. In the items concerning the assessment of the first six suffixes, the parents should indicate the frequency of use for each one by marking one of the following categories: (1) not yet; (2) sometimes; or (3) often. In the item that assesses the use of person marking, the parents should signalize the person mark suffixes that their child uses. In the Galician version, the child receives a score of one point if he/she produces at least three different person mark suffixes in each of the three verbal conjugations; in the Portuguese version, the child receives a score of one point if he/she produces at least three different person mark suffixes in any of the three verbal conjugations. To obtain a total score for the number of regular morphemes produced by each child, each response with ' not yet' was scored with zero and each response with 'sometimes' or 'often' was scored with one.

Finally, syntactic development is measured by one question which asks if the child has already started to combine words, to which the parents should answer using the following response categories: (1) not yet; (2) sometimes; or (3) often. For the purposes of this study, each response with 'not yet' was scored with zero and each response 'sometimes' or 'often' was scored with one.

Authorization for data collection was requested from the Portuguese National Commission of Data Protection. Before filling the inventories, all parents signed an 
informed consent that described the goals of the study and were guaranteed anonymity and confidentiality for the data collected.

\section{Results}

\section{Aim I: To compare the lexical size of children from 16 to 30 months of age assessed with the Portuguese and Galician versions of the CDI}

Given that the Galician and Portuguese versions of the CDI are composed of a different number of words, a proportion of the total number of words produced in each version was calculated for each participant. This proportion was used as an indicator for lexical size. A multiple linear regression analysis was performed, taking language and age as predictors of the lexical size of the toddlers. The interaction term between both predictors was also tested. The model was statistically significant, $F(3,4089)=1187.77$, $p<.001$, and explained approximately $47 \%$ of the variance observed in the lexical size $\left(R^{2}=.466\right.$; Adjusted $\left.R^{2}=.465\right)$. Age and language were significant predictors $(p<.001)$, but the interaction term between age $\times$ language was not significant $(p=.770)$. As Figure 1 depicts, the number of words produced increased with age in both samples, but children in the Galician sample produced a higher proportion of words $($ Mean $=.446 ; \mathrm{SD}=.289)$ than

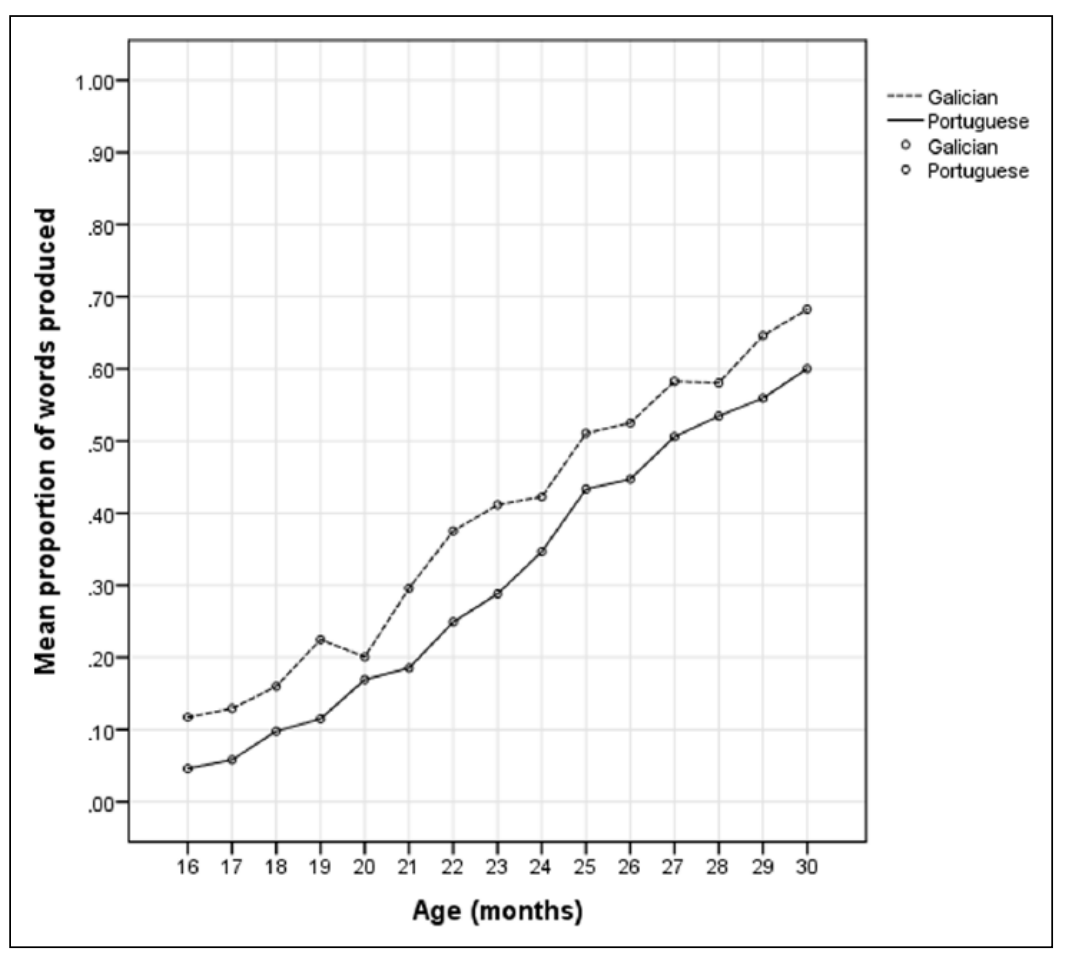

Figure I. Mean proportion of words produced in the Galician and Portuguese samples. 
the children in the Portuguese sample $($ Mean $=.319 ; \mathrm{SD}=.272)$. The regression results also indicated that age made the largest contribution in the model, $\beta=.65, s r^{2}=.13$. Language only had a small contribution to the observed variance in the lexical size, $\beta=.12, s r^{2}=.02$.

\section{Aim 2: To compare the results obtained in one score of syntactic development (combination of words) in children from 16 to 30 months of age in the Portuguese and Galician versions of the CDI}

Figure 2 presents the percentage of children who combine words in each sample. As observed, more than $50 \%$ of the children in the Galician sample started to combine words at 19 months, whereas in the Portuguese sample, this occurred at 20 months. To further investigate the differences in the syntactic development across both samples, a logistic regression analysis on the results obtained in word combination, with language and age as independent variables, was performed. The model significantly predicted word combination, $\chi^{2}(3)=1188.68, p<.001$, Nagelkerke's $R^{2}=.381$. The results indicated a significant effect of age (Odds Ratio $=1.483,95 \% \mathrm{CI}=[1.406-1.564], p<.001$ ), but no

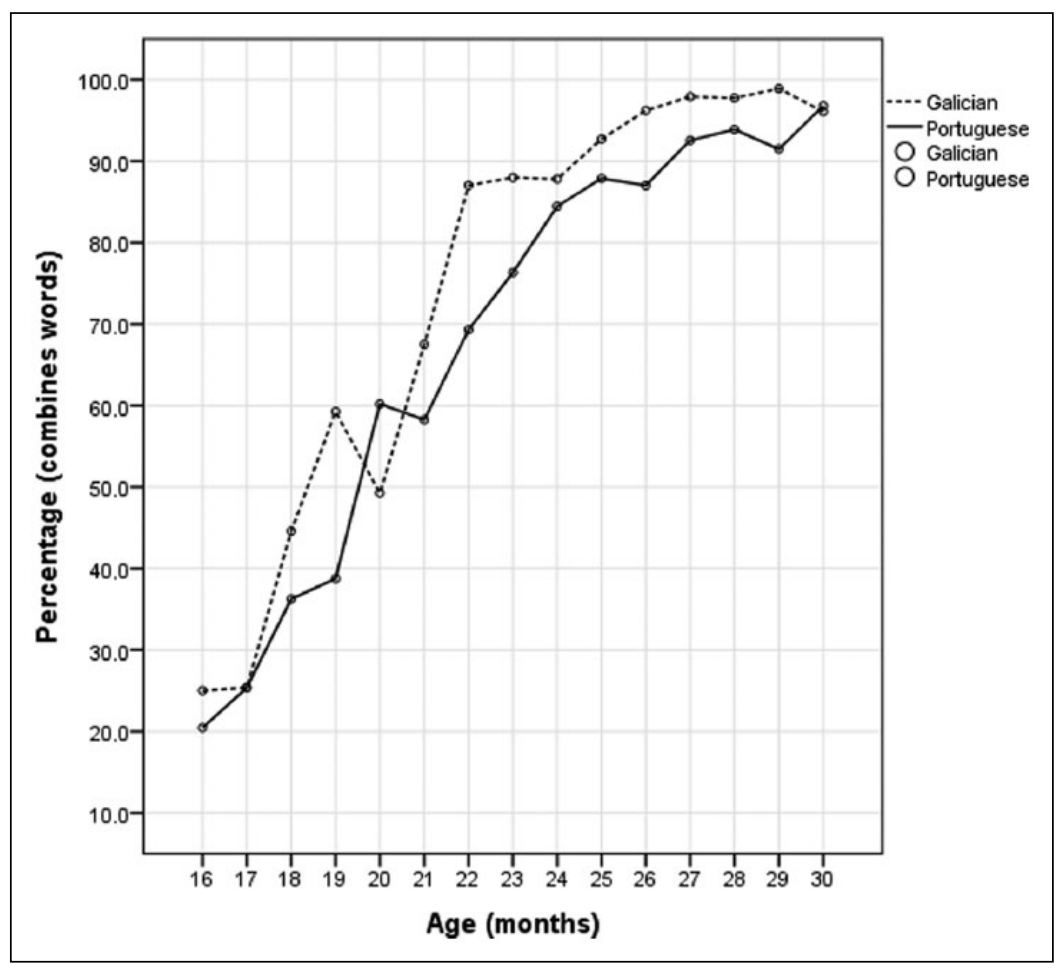

Figure 2. Percentage of children that have started to combine words, by age, in the Galician and Portuguese samples. 
significant effect of language (Odds Ratio $=2.307,95 \% \mathrm{CI}=[0.650-8.190], p=.196$ ). Additionally, no interaction effect was found between age and language (Odds Ratio = $0.942,95 \% \mathrm{CI}=[0.888-1.001], p=.052)$. These results indicate that word combination increases with age and that this occurs similarly in the two samples.

\section{Aim 3: To compare the production of seven regular morphemes in children from 16 to 30 months of age in the Portuguese and Galician versions of the $C D I$}

A multiple linear regression analysis was performed, taking language and age as predictors of the number of morphemes produced by the toddlers. The interaction term between the predictors was also included in the model. The model was statistically significant, $F(3,3775)=868.74, p<.001$, and explained approximately $41 \%$ of the variance observed in the number of morphemes produced $\left(R^{2}=.408\right.$; Adjusted $\left.R^{2}=.408\right)$. Age and language were significant predictors of the number of morphemes produced $(p<.001)$, but the interaction term between age $\times$ language was not significant $(p=.789)$. Once again, age was the main predictor, $\beta=.62, s r^{2}=.12$, whereas language made only a small contribution to the observed variance in the number of morphemes produced, $\beta=.09$, $s r^{2}=.01$. As depicted in Figure 3, the number of regular morphemes produced increased

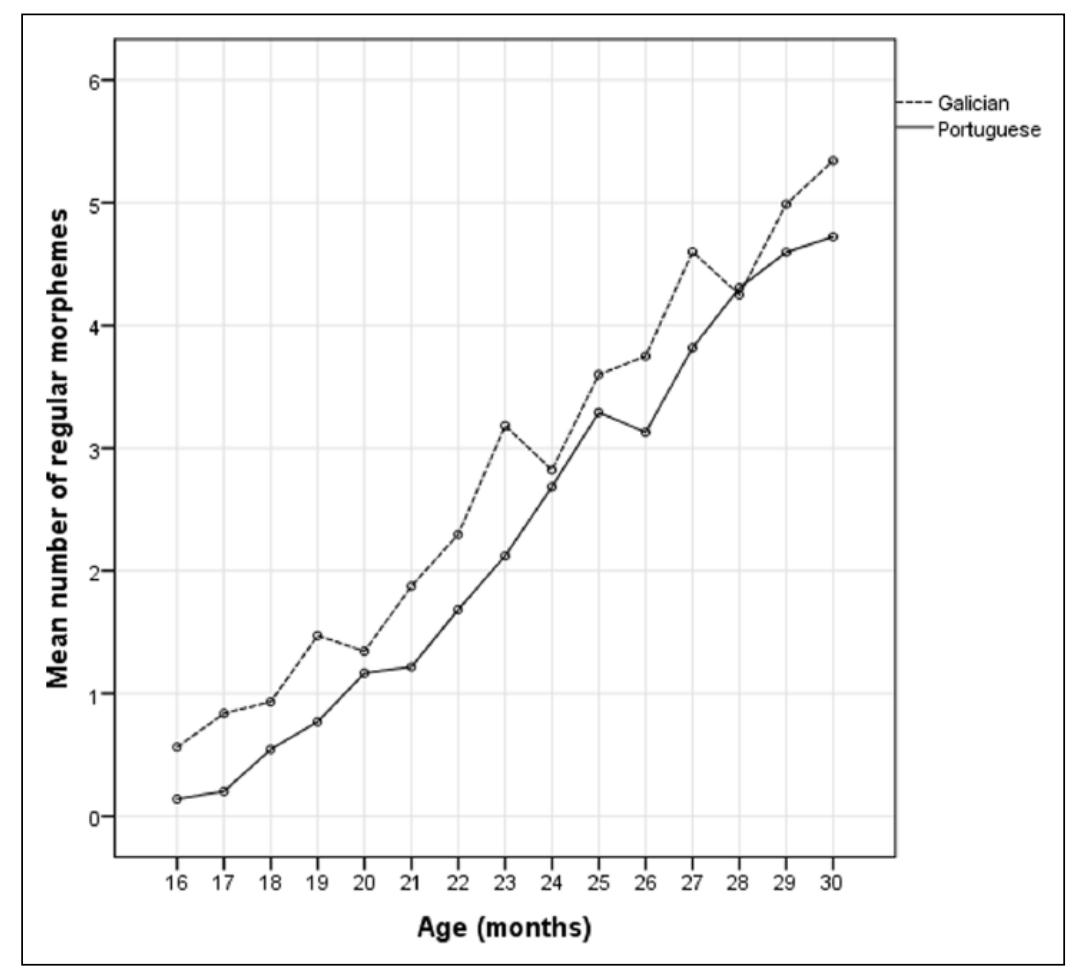

Figure 3. Mean number of regular morphemes produced in the Galician and Portuguese samples. 
with age. However, the toddlers in the Galician sample produced more morphemes (Mean = $3.262, \mathrm{SD}=2.490)$ than those in the Portuguese sample $($ Mean $=2.374, \mathrm{SD}=2.446)$.

\section{Aim 4: To relate the scores obtained in combination of words to the number of words produced and to compare them between languages}

To accomplish the fourth goal, a multiple regression analysis was performed, taking the lexical size (proportion of words produced) as an outcome variable, and word combination, language and age as predictors. The interaction between word combination and language was also tested. The model was statistically significant, $F(4,3898)=1091.23$, $p<.001$, and explained approximately $53 \%$ of the variance observed in the lexical size $\left(R^{2}=.528\right.$; Adjusted $\left.R^{2}=.528\right)$. All three individual predictors were significant $(p<$ $.001)$, but the interaction term between language $\times$ word combination did not reach significance $(p=.088)$. As previously observed, age was the main predictor of lexical size, $\beta=.50, s r^{2}=.18$, followed by word combination, $\beta=.33, s r^{2}=.02$. Language made a very small contribution to the observed variance in lexical size, $\beta=.07, s r^{2}=.001$.

Figure 4 presents the percentage of children in each sample that combine words by lexical size, considering eight intervals in the number of words produced. As can be

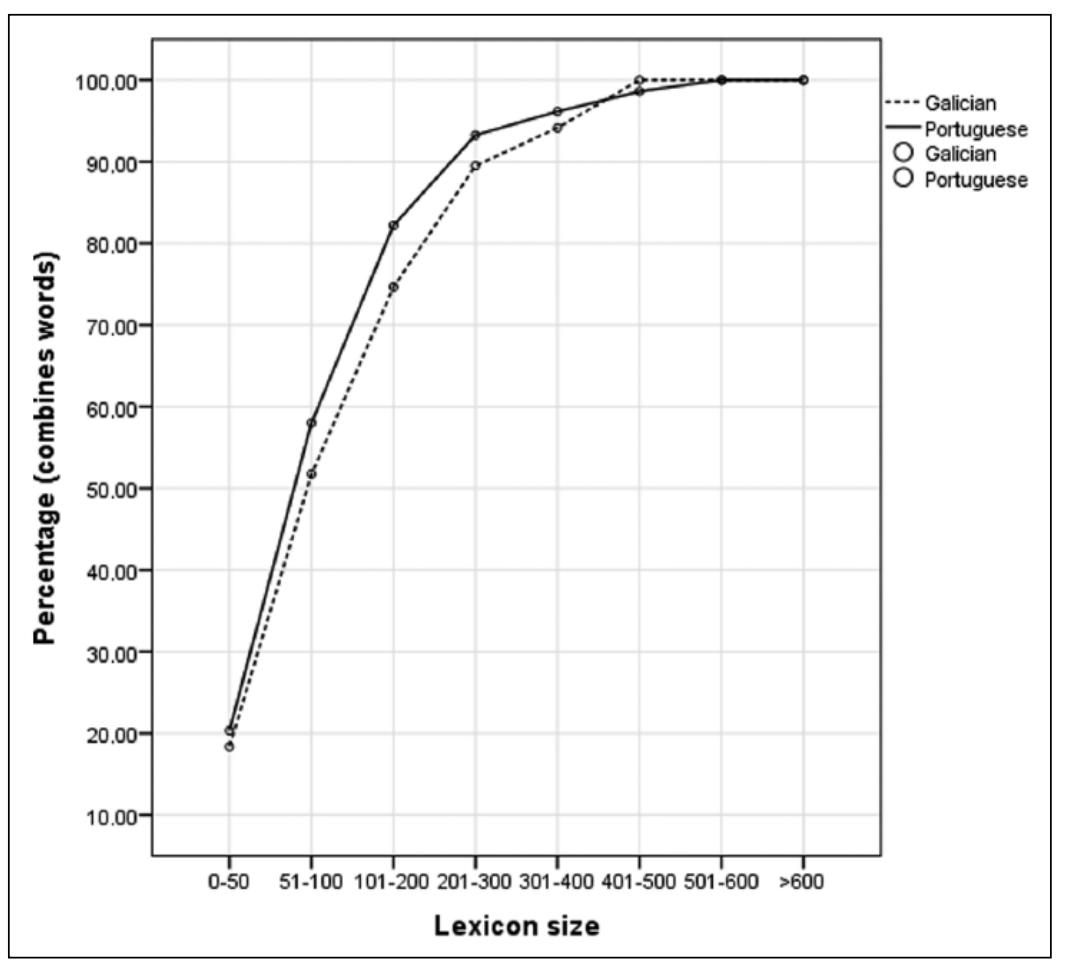

Figure 4. Percentage of children that combine words by lexicon size in the Portuguese and Galician samples. 
observed, in both samples, approximately $50 \%$ of the toddlers with a lexicon size of 51-100 words are able to combine words. At the 301-400 word interval, more than $90 \%$ of the children combine words.

Aim 5: To analyse the age and lexical repertoire associated with the production of the different regular morphemes by $50 \%$ of the children (early acquisition) in each age group and to analyse the developmental trends in both languages

Figure 5 presents the percentage of children that produce each of the seven suffixes in the Galician and Portuguese samples. Taking the acquisition of the morpheme by $50 \%$ of the sample as the reference criterion, we can see that some similarities and differences occur between the two samples. As expected, the first morpheme that the children use is the gender mark: 50\% of the Galician sample used it at 19 months, whereas in the Portuguese sample, this occurred at 23 months. Plural seems to be acquired later and both samples are similar in terms of the age of acquisition: $58 \%$ of the Galician sample used plural at

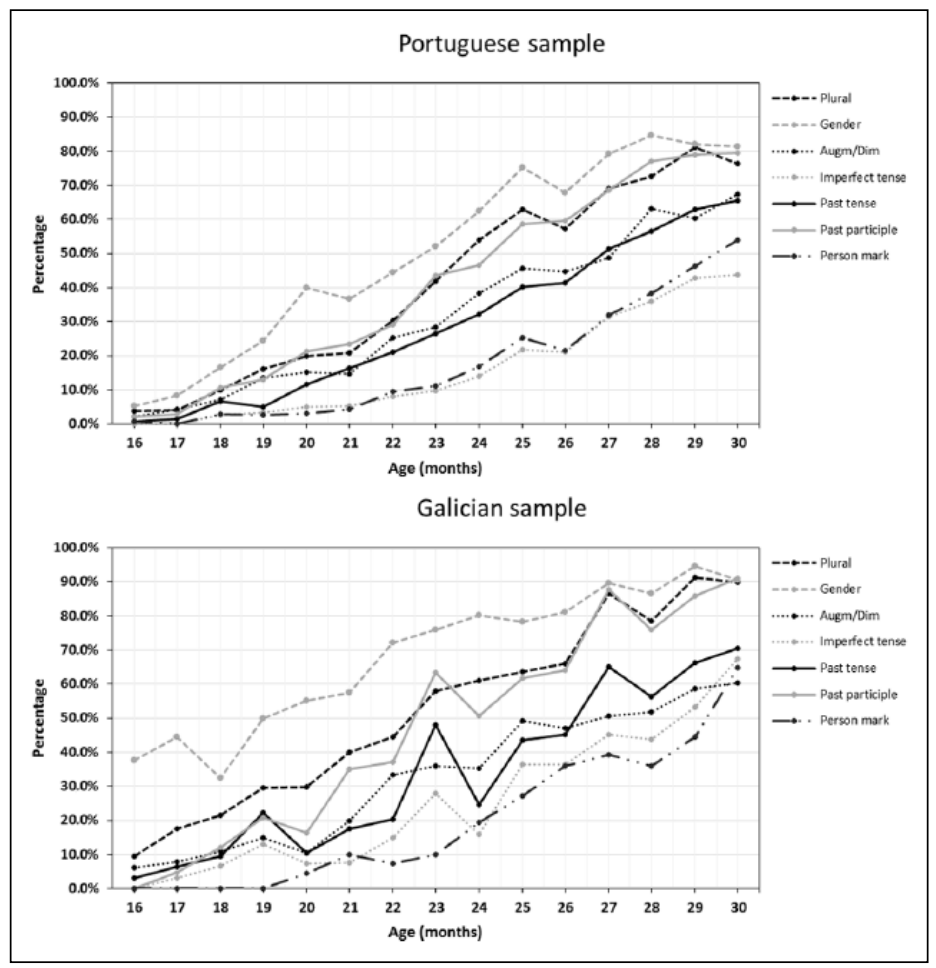

Figure 5. Percentage of children that produce suffixes by age in the Portuguese and Galician samples. 


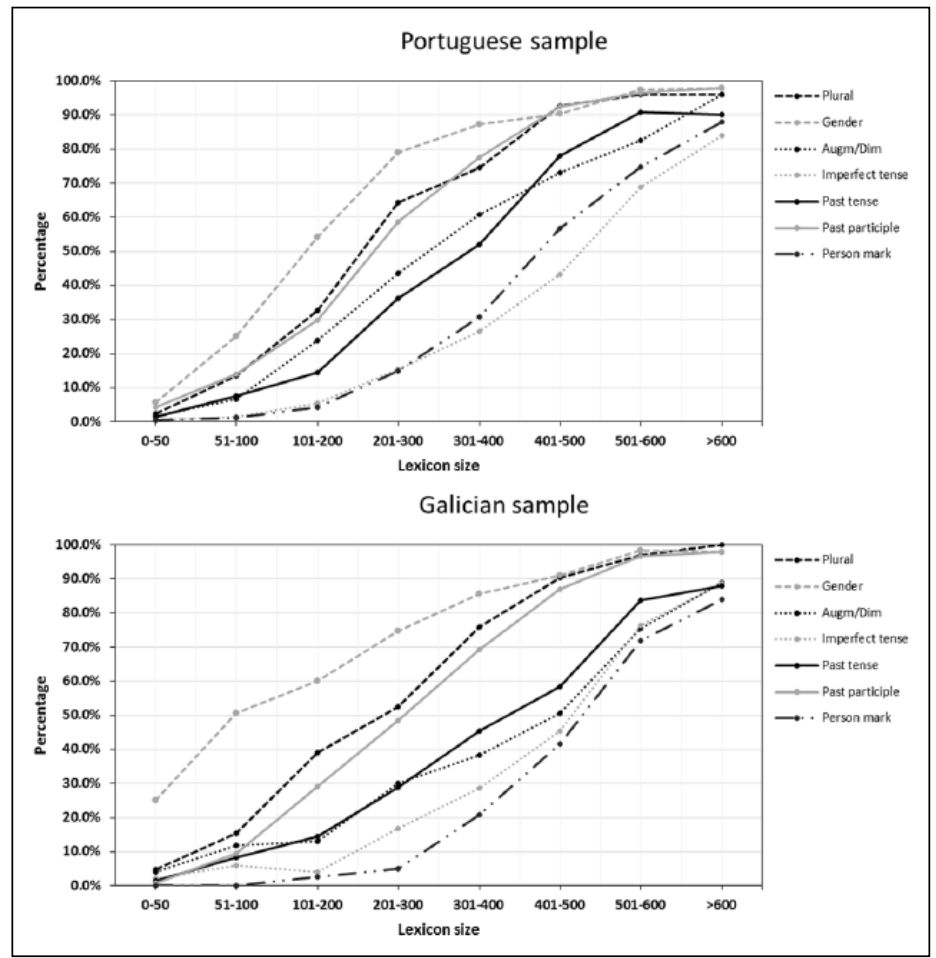

Figure 6. Percentage of children that produce suffixes by lexicon size in the Portuguese and Galician samples.

23 months, while 54\% of the Portuguese sample used it at 24 months. The remaining five regular morphemes seem to have their use generalized (by more than half of the sample) at similar ages in both samples: the past participle at approximately $23-25$ months, the augmentative/diminutive morphemes and the past tense mark at 27 months, the person mark at 30 months, and the imperfect tense at approximately 29-30 months of age.

Figure 6 presents the percentage of children that produce the morphemes by lexicon size (number of words produced) in each sample. Considering the 301-400 interval of words produced, more than half of both samples produce gender, plural and the past participle morphemes. At least $50 \%$ of the Portuguese sample that produces between 301 and 400 words also uses the augmentative/diminutive morphemes and the past tense. The production of gender appears to be accompanied by a lower lexicon size: half of the Galician sample that has a lexicon size of 51-100 words and more than half of the Portuguese sample that has a lexicon size of 101-200 words use gender morphemes. However, the imperfect tense and the person mark production seem to be accompanied by a higher lexicon size: in both samples the children seem to produce at least 401 words before approximately half of the children use these morphemes. 


\section{Discussion and conclusions}

The first three specific goals of this study were to compare lexical size, syntactic development and the production of seven morphemes across Galician and Portuguese samples in children from 16 to 30 months of age. The results indicated that age was a significant predictor of all three indicators for lexical, syntactic and morphological development with high effect size values. This indicates that, as expected, children produce more words and more morphemes and that the combination of words starts to be more frequent as they grow older. The results also indicated a significant effect of language in the number of words and in the number of morphemes produced. However, the effect size values for these effects are very low, suggesting that these differences are not meaningful.

The fourth goal of this study was to relate the scores obtained in word combination to the number of words produced and to compare them for both languages. The results indicated a significant effect of word combination on the lexical size of children. Our data are convergent with the notion of lexical critical mass (Bates \& Goodman, 1997; Marchman \& Bates, 1994). Similarly to other studies developed in various languages which also use parental reports such as the CDI, our results indicate that children need to have a substantial stock of words to begin combining them (Bassano \& van Geert, 2007; Caselli et al., 1999; Devescovi et al., 2005; Fenson et al., 1994). The results of our study indicated that, similar to results obtained with English-speaking toddlers (Fenson et al., 1994), some children are able to combine words even at relatively small lexical sizes (approximately 100 words) and that almost all of the children with large lexical sizes demonstrate this syntactic ability. These results are strikingly similar for European Portuguese and Galician.

The fifth goal of this study was to analyse the age and lexical repertoire associated with the production of the different regular morphemes by $50 \%$ of the children (early acquisition) in each age group and to analyse the developmental trends in both languages. Gender and plural morphemes seem to be the first ones to have their use generalized in both samples, while person mark, imperfect and the past tenses only seem to be acquired close to two and a half years of age. These results are consistent with those observed in other languages, such as German (Szagun et al., 2006). In the case of Spanish, another Romance language, gender mark is the first to appear as well (Mariscal \& Gallo, 2006). In general terms, the order of acquisition of the morphemes studied is practically the same for Portuguese and Galician, and similar to those found for Spanish (Mariscal \& Gallo, 2006).

When exploring the relationship between the lexical size and the use of different morphemes, we must consider the richness of both languages. European Portuguese and Galician are both rich languages with regular morphology. Regular morphology acquisition occurs early and there is some evidence that children use morphological cues to map the meaning of new words (Kim, Mcgregor, \& Thompson, 2000; Slobin, 1973). Therefore, it is plausible that the production of some morphemes is accompanied by relatively small lexical sizes in languages with a high degree of regular morphology. Our results indicate that a high variability in lexical size is associated with the production of different morphemes. While the production of gender morphemes is accompanied by a relatively small lexical size, especially in the Galician sample (51-100 words), the 
production of verbal morphemes is related to a much larger lexical size. For example, in both samples, the production of the imperfect tense and the person mark start to be frequent only after the production of approximately 400 words. These results highlight the necessity of considering contextual variables, such as the frequency of the variations in oral language directed to children, not simply the richness or the regularity of the language. For example, a study performed by Xanthos et al. (2011) conducted with children from very different social contexts who were acquiring nine different languages, highlights an important variable frequently underestimated - the variation in child-directed speech. Their results show that the morphological richness of the child-directed speech has a strong correlation with the speed of morphological development in child speech. Future studies analysing the relationship between lexical, morphological and syntactical development in Galician and European Portuguese should take into account the influence of the child-directed speech.

One limitation of this study is the use of a measure of syntactic development - word combination - assessed with only one single question, that enquired whether the child had already begun to combine words. Although we acknowledge that this measure does not capture the full complexity of the toddlers' syntactic development, it does however present two main advantages: (a) it is a simple and objective question that asks the parents to indicate the presence of a behaviour that is easily recognizable, which is particularly important when using parents with low educational levels as informants; (b) in cross-linguistic comparisons, using this question guarantees that the measure is exactly the same and that increases the reliability of the information collected. Moreover, as Fenson and colleagues indicate (2000), 'the ability to combine words has been noted as a developmentally significant milestone that sets the stage for a wide array of syntactic and semantic developments as well as general vocabulary development' (p. 99). The results of our study provide additional support for this claim, given that a significant relationship between word combination and lexical size was found.

The difference in the maternal education levels of the Portuguese and the Galician samples is also a limitation of this study given that some literature has reported that children of more educated mothers are at an advantage in regard to the variety of linguistic abilities (e.g. Reese \& Read, 2000; Schults, Tulviste, \& Konstabel, 2012). However, all the differences found in our study are favourable to the Galician sample, which is composed of mothers with lower educational levels than the Portuguese sample. This suggests that the differences are not due to the educational background factor but are probably an attribute of language characteristics.

One of the main obstacles for cross-linguistic comparisons using the CDI versions of different languages is the different number of items that comprises the word production checklists of the different versions. This variability reflects the specificities of each language but makes it difficult to ascertain if the observed differences between languages are an artefact introduced by this characteristic of the measure. For this reason, the proportion of the total number of words available in each checklist that each child produced was used instead of a simple total score. Using this methodology, we can conclude that lexical, grammatical and morphological development in 16- to 30-month-old toddlers is very similar in Galician and European Portuguese, although the Galician sample shows a slightly higher score across this age interval. Moreover, this study highlights the 
interdependence of lexical and grammatical abilities of toddlers, by showing a close relationship between the number of words produced, the ability to combine words and the ability to use seven regular morphemes.

\section{Declaration of conflicting interests}

The author(s) declared no potential conflicts of interest with respect to the research, authorship, and/or publication of this article.

\section{Funding}

The author(s) disclosed receipt of the following financial support for the research, authorship, and/ or publication of this article: This research was supported by European Regional Development Fund (FEDER) through the European programme COMPETE (Operational Programme for Competitiveness Factors) under the National Strategic Reference Framework (QREN) - FCOMP01-0124-FEDER-029556 and from FCT (Fundação para a Ciência e a Tecnologia PTDC/MHC$\mathrm{PED} / 4725 / 2012)$. The third and the fourth authors are also supported by grants SFRH/ BPD/102549/2014 and SFRH/BD/86795/2012 from FCT.

\section{References}

Andonova, E. (2015). Parental report evidence for toddlers' grammar and vocabulary in Bulgarian. First Language, 35, 126-136.

Bassano, D., \& van Geert, P. (2007). Modeling continuity and discontinuity in utterance length: A quantitative approach to changes, transitions and intra-individual variability in early grammatical development. Developmental Science, 19, 588-612.

Bates, E., Bretherthon, I., \& Snyder, L. (1988). From first words to grammar: Individual differences and dissociable mechanisms. New York, NY: Cambridge University Press.

Bates, E., \& Goodman, J. C. (1997). On the inseparability of grammar and the lexicon: Evidence from acquisition, aphasia and real-time processing. Language and Cognitive Processes, 12, 507-584.

Bates, E., \& Goodman, J. C. (1999). On the emergence of grammar from the lexicon. In B. MacWhinney (Ed.), The emergence of language (pp. 29-70). Mahwah, NJ: Lawrence Erlbaum.

Bates, E., Marchman, V., Thal, D., Fenson, L., Dale, P., Reznick, S., . . . Hartung, J. (1994). Developmental and stylistic variation in the composition of early vocabulary. Journal of Child Language, 21, 85-123.

Bleses, D., Vach, W., Slott, M., Wehberg, S., Thomsen, P., Madsen, T. O., \& Basbøll, H. (2008). Early vocabulary development in Danish and other languages: A CDI-based comparison. Journal of Child Language, 35, 619-650.

Caselli, C., Casadio, P., \& Bates, E. (1999). A comparison of the transition from first words to grammar in English and Italian. Journal of Child Language, 26, 69-111.

Conboy, B. T., \& Thal, D. J. (2006). Ties between the lexicon and grammar: Cross-sectional and longitudinal studies of bilingual toddlers. Child Development, 77, 712-735.

Dale, P. S., \& Goodman, J. C. (2005). Commonality and individual differences in vocabulary growth. In M. Tomasello, \& D. I. Slobin (Eds.), Beyond nature-nurture: Essays in honor of Elizabeth Bates (pp. 41-80). London, England: Lawrence Erlbaum.

Devescovi, A., Caselli, M. C., Marchione, D., Pasqualetti, P., Reilly, J., \& Bates, E. (2005). A crosslinguistic study of the relationship between grammar and lexical development. Journal of Child Language, 32, 759-786.

Dromi, E. (1987). Early lexical development. New York, NY: Cambridge University Press. 
Fenson, L., Dale, P. S., Reznick, J. S., Bates, E., Thal, D. J., \& Pethick, S. J. (1994). Variability in early communicative development. Monographs of the Society for Research in Child Development, 59(5), 1-173.

Fenson, L., Marchman, V., Thal, D., Dale, P., Reznick, J., \& Bates, E. (2007). MacArthur-Bates Communicative Development Inventories: Users guide and technical manual (2nd ed.). Baltimore, MD: Paul H. Brookes.

Fenson, L., Pethick, S., Renda, C., Cox, J. L., Dale, P. S., \& Reznick, J. S. (2000). Short-form versions of the MacArthur Communicative Development Inventories. Applied Psycholinguistics, $21,95-115$.

Kim, M., Mcgregor, K. K., \& Thompson, C. K. (2000). Early lexical development in Englishand Korean-speaking children: Language-general and language-specific patterns. Journal of Child Language, 27, 225-254.

Labrell, F., van Geert, P., Declercq, C., Baltazart, V., Caillies, S., Olivier, M., \& Le SournBissaoui, S. (2014). 'Speaking volumes': A longitudinal study of lexical and grammatical growth between 17 and 42 months. First Language, 34, 97-124.

Marchman, V., \& Bates, E. (1994). Continuity in lexical and morphological development: A test of the critical mass hypothesis. Journal of Child Language, 21, 339-366.

Mariscal, S., \& Gallego, C. (2012). The relationship between early lexical and grammatical development in Spanish: Evidence in children with different linguistic levels. The Spanish Journal of Psychology, 15, 112-123.

Mariscal, S., \& Gallo, P. (2006). Evaluación del desarrollo gramatical temprano en la adaptación española de los Inventarios MacArthur [Evaluation of the grammar development in the Spanish adaptation of the MacArthur Inventories]. Estudios de Psicología, 27, 153-173.

Nelson, K. (1973). Structure and strategy in learning to talk. Monographs of the Society for Research in Child Development, 38(1-2), 1-135.

Pérez-Pereira, M. (2008). Early Galician/Spanish bilingualism: Contrasts with monolingualism. In C. Pérez-Vida, M. Juan-Garau, \& A. Bel (Eds.), A portrait of the young in the new multilingual Spain (pp. 39-62). Clevedon, UK: Multilingual Matters.

Pérez-Pereira, M., \& García-Soto, X. R. (2003). El diagnóstico del desarrollo comunicativo en la primera infancia: Adaptación de las escalas MacArthur al gallego [Diagnosis of communicative development in infancy: Adapting the MacArthur scales into Galician]. Psicothema, 15, 352-361.

Pérez-Pereira, M., \& Resches, M. (2011). Concurrent and predictive validity of the Galician CDI. Journal of Child Language, 38, 121-140.

Plunkett, K., \& Marchman, V. (1993). From rote-learning to system building: The acquisition of morphology in children and connectionist nets. Cognition, 48, 21-69.

Reese, E., \& Read, S. (2000). Predictive validity of the New Zealand MacArthur Communicative Development Inventory: Words and Sentences. Journal of Child Language, 27, 255-266.

Schults, A., Tulviste, T., \& Konstabel, K. (2012). Early vocabulary and gestures in Estonian children. Journal of Child Language, 39, 664-686.

Serrat, M., Sanz-Torrent, M., \& Bel, A. (2004). Aprendizaje del lenguaje y desarrollo gramatical: Vocabulario verbal, aceleración léxica y complejidad sintáctica [Language learning and grammar development: Verbal vocabulary, lexical acceleration and syntactical complexity]. Anuario de Psicología, 35, 221-234.

Silva, C., Cadime, I., Ribeiro, I., Santos, S., Santos, A. L., \& Viana, F. L. (2017). Parents' reports of lexical and grammatical aspects of toddlers' language in European Portuguese: Developmental trends, age and gender differences. First Language, 37, 271-288. 
Simonsen, H. G., Kristoffersen, K. E., Bleses, D., Wehberg, S., \& Jorgensen, R. N. (2014). The Norwegian Communicative Development Inventories: Reliability, main developmental trends and gender differences. First Language, 34, 3-23.

Slobin, D. I. (1973). Cognitive prerequisites for the development of grammar. In C. A. Ferguson, \& D. I. Slobin (Eds.), Studies of child language development (pp. 175-208). New York, NY: Holt, Rinehart \& Winston.

Stolt, S., Haataja, L., Lapinleimu, H., \& Lehtonen, L. (2008). Early lexical development of Finnish children: A longitudinal study. First Language, 28, 259-279.

Szagun, G., Steinbrink, C., Franik, M., \& Stumper, B. (2006). Development of vocabulary and grammar in young German-speaking children assessed with a German language development inventory. First Language, 26, 259-280.

Thordardottir, E. T., Weismer, S. E., \& Evans, J. L. (2002). Continuity in lexical and morphological development in Icelandic and English-speaking 2-year-olds. First Language, 22, 3-28.

Viana, F. L., Cadime, I., Silva, C., Santos, S., Lima, R., Ribeiro, I., . . Lucas, I. (in press). Os Inventários de Desenvolvimento Comunicativo de MacArthur-Bates. Manual técnico [The MacArthur-Bates Communicative Development Inventories: Technical manual]. Braga, Portugal: Centro de Investigação em Estudos da Criança da Universidade do Minho.

Villalva, A. (2009). Morfologia do Português [Portuguese morphology]. Lisboa, Portugal: Universidade Aberta.

Xanthos, A., Laaha, S., Gillis, S., Stephany, U., Aksu-Koc, A., Christofidou, A., . . . Dressler, W. U. (2011). On the role of morphological richness in the early development of noun and verb inflection. First Language, 31, 461-479. 